\title{
A Simple Test for PPP Among Traded Goods*
}

\author{
Philip Hans Franses ${ }^{\dagger}$ \\ Econometric Institute \\ Erasmus University Rotterdam
}

\author{
Dick van Dijk ${ }^{\ddagger}$ \\ Econometric Insitute \\ Erasmus University Rotterdam
}

\section{ECONOMETRIC Institute Report EI 2002-2}

January 2002

\begin{abstract}
The so-called Balassa-Samuelson model implies that relative prices of nontraded goods may be nonstationary and, hence, that PPP should preferably be tested on real exchange rates based on prices of traded goods only. We propose a simple test for PPP among traded goods which can be applied to real exchange rates based on prices of all (that is, both traded and non-traded) goods. We show through simulations that the test is reliable for a sample size commonly considered in practice. Upon applying the test to bilateral real exchange rates based on the general CPI among a group of industrialized countries during the recent float, we find little evidence in favor of PPP among traded goods. This does not change when we use real exchange rates based on various components of the CPI.
\end{abstract}

Keywords: purchasing power parity; unit roots; unidentified nuisance parameters.

JEL classification: F30; F40; C12.

${ }^{*}$ The second author thanks the Netherlands Organization for Scientific Research (N.W.O.) for its financial support.

${ }^{\dagger}$ Econometric Institute, P.O. Box 1738, NL-3000 DR Rotterdam, The Netherlands, E-mail: franses@few. eur.nl

${ }^{\ddagger}$ Econometric Institute, P.O. Box 1738, NL-3000 DR Rotterdam, The Netherlands, Tel.: +3110-4081263, Fax: +31-10-4089162, E-mail: djvandijk@few.eur.nl (corresponding author) 


\section{Introduction}

Purchasing Power Parity [PPP] is generally believed to hold as a long-run equilibrium relationship. However, the empirical support for PPP, when examined by unit root tests, is not overwhelming ${ }^{1}$. In particular, such unit root tests typically suggest nonstationarity of real exchange rates when applied to data from the post-Bretton Woods era. This finding often is attributed to the lack of power of standard unit root and cointegration tests in small samples and/or against certain near-nonstationary alternatives. To surmount this lack of power, several different strategies have been devised, such as the use of long spans of data ${ }^{2}$ and the use of panel unit root tests ${ }^{3}$. Although these approaches lead to more evidence supporting PPP, they are not without criticism. The use of long spans of data inevitably means mixing data from fixed and floating (nominal) exchange rate regimes. It seems likely that real exchange rates also behave differently under such different exchange rate regimes, see Grilli and Kaminsky (1991) for an elaborate discussion. O'Connell (1998) criticizes the results from studies which employ panel unit root tests for not correcting for the comovements of the real exchange rates in the panels used. Taking this into account greatly reduces the statistical support for PPP, see also Pedroni (2001) and Wu and Wu (2001). Additionally, Sarno and Taylor (1998) and Taylor and Sarno (1998) argue that panel unit root tests may be misleading as rejection of the null hypothesis (which is non-stationarity of all real exchange rates in the panel) may occur if only a small number of the series considered actually is stationary.

Next to statistical arguments, there are also economic explanations for the failure to find empirical evidence in favor of PPP. Currently, the most popular among these is the existence of barriers to trade, such as tariffs and transportation costs. Several theoretical models have been developed showing that such market frictions lead to nonlinear adjustment in real exchange rates to the PPP equilibrium rate, see Benninga and Protopapadakis (1988), Dumas (1992) and Sercu, Uppal and Van Hulle (1995), among others. In particular, the strength of mean reversion increases with the deviation from parity, as the profits from goods arbitrage, which is generally thought to be the ultimate force behind maintaining PPP, do not make up for the costs involved in the necessary transactions for small deviations from the presumed

\footnotetext{
${ }^{1}$ Comprehensive surveys of the voluminous literature on PPP can be found in Froot and Rogoff (1995), Rogoff (1996), and, more recently, Sarno and Taylor (2001).

${ }^{2}$ See Abuaf and Jorion (1990), Ardeni and Lubian (1991), Edison (1987), Glen (1992), Grilli and Kaminsky (1991), and Lothian and Taylor (1996), among others.

${ }^{3}$ See Frankel and Rose (1996), Lothian (1997), MacDonald (1996), Oh (1996), Papell (1997), Papell and Theodoridis (1998), Taylor and Sarno (1998) and Wu (1996), among others.
} 
equilibrium real exchange rate. This has recently led to an outburst of empirical papers using nonlinear time series models to accommodate such effects ${ }^{4}$.

Another well-known and intuitively plausible economic explanation for the lack of empirical support for PPP is the presence of non-traded goods in the price indices used to construct real exchange rates. Given that PPP is supposed to be maintained by international commodity arbitrage, it follows immediately that this applies to traded goods only. Moreover, as already shown by Balassa (1964) and Samuelson (1964), permanent productivity shocks can lead to permanent changes in the relative prices of traded and non-traded goods, which in turn implies that the real exchange rate has a nonstationary component. The empirical evidence for the Balassa-Samuelson effect is mixed, see Canzoneri, Cumby and Diba (1999), De Gregorio, Giovannini and Wolf (1994), and Heston, Nuxoll and Summers (1994) for some favorable results. Engel (1999) and Rogers and Jenkins (1995) document, however, that changes in relative prices of non-traded goods appear to account for only a small fraction of real exchange rate changes, suggesting that the Balassa-Samuelson is not a very important factor in explaining the empirical failure of PPP. Moreover, Engel (2000) shows that, under these circumstances, standard unit root tests suffer from large size distortions, especially when applied to long historical time series, see also Ng and Perron (2001). Note that this finding actually makes it even more puzzling that the support for PPP is rather scarce.

In the Balassa-Samuelson model, PPP is assumed to hold among traded goods due to the forces of international commodity arbitrage, such that the relative prices of traded goods are stationary and mean-reverting. Several studies show, however, that PPP may fail even among traded goods, see Canzoneri et al. (1999), Engel (1993), Engel and Rogers (1996, 2001), and Parsley and Wei (2001), among others. Apart from the impediments to trade mentioned before, another explanation for this finding is local-currency-pricing [LCP] or pricing-to-market [PTM], meaning to say that producers selling abroad set prices in the currency of consumers rather than their own. Under LCP, changes in nominal exchange rates do not lead to adjustments in goods prices in the local market, that is, there is no pass-through of exchange rate changes. Feenstra and Kendall (1997), Haskel and Wolf (2001), and Knetter (1993), among others, document the empirical relevance of LCP. Hence, it seems reasonable that PPP among traded goods should not simply be assumed,

\footnotetext{
${ }^{4}$ See Baum, Caglyan and Barkoulas (2001), Lo and Zivot (2001), Michael, Nobay and Peel (1997), Obstfeld and Taylor (1997), O'Connell and Wei (2002), Sarantis (1999), Taylor, Peel and Sarno (2001) and Taylor (2001). It should be noted that many of these papers consider the relative price of individual goods and therefore actually test the Law of One Price [LOP].
} 
but rather should be tested. In this paper we show how this can be done with real exchange rates based on aggregate price indices, despite the fact these aggregate indices for a significant portion consist of non-traded goods, and therefore contain a nonstationary component. We show that this is no problem, and that the resultant test is simple, reliable and useful.

The paper proceeds as follows. In Section 2, we briefly summarize the consequences of the Balassa-Samuelson effect on real exchange rates based on price indices which include non-traded goods. In this section we also discuss how PPP among traded goods can be tested with such general real exchange rates. In Section 3, we apply the tests to real exchange rates and relative prices of several good categories with different degree of tradability across 13 developed countries. We find very little support for PPP, not even among traded goods. Finally, Section 4 concludes.

\section{Testing for PPP while allowing for the Balassa- Samuelson effect}

In this section we first briefly summarize the consequences of the intuitively plausible Balassa-Samuelson effect on testing for PPP among traded goods when general price indices are used to construct real exchange rates. Next, we discuss a simple statistical test method, and we show that is useful and reliable.

\subsection{Incorporating the Balassa-Samuelson effect}

Let $q_{t}$ denote the logarithm of the real exchange rate, that is,

$$
q_{t}=s_{t}+p_{t}^{*}-p_{t}
$$

where $s_{t}$ is the logarithm of the nominal exchange rate, expressed in numbers of units of domestic currency needed to purchase one unit of foreign currency, and where $p_{t}$ and $p_{t}^{*}$ denote the logarithms of the domestic and foreign general price indices, respectively. These price indices are assumed to be geometric averages of traded and non-traded goods, that is,

$$
\begin{aligned}
& p_{t}=(1-\alpha) p_{t}^{T}+\alpha p_{t}^{N} \quad \text { and } \\
& p_{t}^{*}=(1-\beta) p_{t}^{T *}+\beta p_{t}^{N *}
\end{aligned}
$$

where $p_{t}^{T}$ and $p_{t}^{N}$ denote the logarithms of the domestic price indices of traded and non-traded goods and $\alpha$ is the weight of non-traded goods in the general domestic 
price index $p_{t}$, while $p_{t}^{T *}, p_{t}^{N *}$, and $\beta$ are defined similarly for the foreign country. Combining (2) and (3) with (1) allows the real exchange rate $q_{t}$ to be decomposed as

$$
\begin{aligned}
& q_{t}=x_{t}+y_{t}, \\
& x_{t}=s_{t}+p_{t}^{T *}-p_{t}^{T}, \\
& y_{t}=\beta\left(p_{t}^{N *}-p_{t}^{T *}\right)-\alpha\left(p_{t}^{N}-p_{t}^{T}\right) .
\end{aligned}
$$

In the Balassa-Samuelson model, permanent shocks to the relative productivity in traded and non-traded goods sectors lead to permanent changes in the relative prices of traded and non-traded goods. In present-day time series terminology, this implies that $y_{t}$ is a non-stationary process. Consequently, the question of interest when testing for PPP is then whether the traded goods component $x_{t}$ is stationary or not, or put differently, whether $x_{t}$ contains a unit root or not. This can be represented formally, for example, by assuming that the stochastic processes for $y_{t}$ and $x_{t}$ are given by

$$
\begin{aligned}
& y_{t}=y_{t-1}+\varepsilon_{t}, \\
& x_{t}=\phi x_{t-1}+\eta_{t}, \quad \text { with }-1<\phi \leq 1,
\end{aligned}
$$

where $\varepsilon_{t}$ and $\eta_{t}$ are i.i.d. random variables with mean zero and variances $\sigma_{\varepsilon}^{2}$ and $\sigma_{\eta}^{2}$, respectively, and with contemporaneous correlation $\rho=\sigma_{\varepsilon \eta} /\left(\sigma_{\varepsilon} \sigma_{\eta}\right)$. The null hypothesis of interest is in this case given by $\mathrm{H}_{0}: \phi=1$, which is to be tested against the alternative $\mathrm{H}_{1}: \phi<1$. In the sequel of this section we put forward a simple test for this hypothesis based on data for $q_{t}$ only, where $q_{t}=x_{t}+y_{t}$.

\section{$2.2 \quad$ A simple statistical test for PPP among traded goods}

Proceeding from the above results, it is straightforward to show that (7) and (8) imply that $q_{t}=x_{t}+y_{t}$ can be represented as an $\operatorname{ARMA}(1,1)$ process,

$$
\Delta q_{t}=\phi \Delta q_{t-1}+u_{t}+\theta u_{t-1}
$$

where $\Delta$ denotes the first differencing operator defined as $\Delta q_{t} \equiv q_{t}-q_{t-1}$ and $u_{t} \sim$ i.i.d $\left(0, \sigma_{u}^{2}\right)$. The moving average parameter $\theta$ is related to the parameters of the components $x_{t}$ and $y_{t}$ by $^{5}$

$$
\frac{\theta}{1+\theta^{2}}=\frac{-\phi \sigma_{\varepsilon}^{2}-\sigma_{\eta}^{2}-(1+\phi) \sigma_{\varepsilon \eta}}{\left(1+\phi^{2}\right) \sigma_{\varepsilon}^{2}+2 \sigma_{\eta}^{2}+2(1+\phi) \sigma_{\varepsilon \eta}} .
$$

\footnotetext{
${ }^{5}$ It is perhaps useful to mention that the corresponding expression for $\theta$ in Engel (2000) contains a misprint.
} 
From (10), it is easy to see that under the null hypothesis $\mathrm{H}_{0}: \phi=1$, it holds that $\frac{\theta}{1+\theta^{2}}=-\frac{1}{2}$, which uniquely implies that $\theta=-1$. In that case, the autoregressive and moving average component in (9) cancel, and $q_{t}$ reduces to a random walk

$$
\Delta q_{t}=u_{t}
$$

Hence, the null hypothesis implies (11), while the alternative hypothesis implies (9). In sum, testing for PPP among traded goods in the presence of the BalassaSamuelson effectively amounts to testing the null hypothesis of an $\operatorname{ARMA}(0,0)$ representation of the first differences of the real exchange rate $q_{t}$ as in (11) against the alternative of an $\operatorname{ARMA}(1,1)$ representation as in (9).

Testing $\operatorname{ARMA}(0,0)$ against $\operatorname{ARMA}(1,1)$ is an intriguing statistical problem as there are so-called unidentified nuisance parameters under the null hypothesis. As discussed in general by Andrews and Ploberger (1994) and Hansen (1996), among others, conventional test statistics cannot be used in that case, and other strategies are required. Interestingly, Andrews and Ploberger (1996) developed statistical tests specifically designed for our testing problem. To describe their test statistics, consider the general $\operatorname{ARMA}(1,1)$ model for a time series $z_{t}$,

$$
z_{t}=(\pi+\lambda) z_{t-1}+e_{t}-\pi e_{t-1}, \quad t=2,3, \ldots, T
$$

where $T$ is the sample size, and where $e_{t}$ denotes a white noise process. The interest is in testing the null hypothesis of white noise against the alternative of $\operatorname{ARMA}(1,1)$ type serial correlation in $z_{t}$, given by

$$
\mathrm{H}_{0}: \lambda=0 \text { and } \mathrm{H}_{1}: \lambda \neq 0 \text {, }
$$

respectively. The problem of unidentified nuisance parameters under the null hypothesis is immediately clear from the representation in (12), because in case $\lambda=0$, the model reduces to $z_{t}=e_{t}$ and the parameter $\pi$ has disappeared.

The testing approach devised by Andrews and Ploberger (1996) amounts to first computing a standard likelihood ratio (LR) or Lagrange Multiplier (LM) statistic for a large number of different given values of $\pi$, and then computing a certain functional of these "pointwise" statistics. Specifically, they consider the supremum, 
average and exponential statistics, given by

$$
\begin{aligned}
\operatorname{SupF} & =\sup _{\pi \in \Pi} F_{T}(\pi) \\
\mathrm{AveF} & =\frac{1}{n_{\pi}} \sum_{\pi \in \Pi} F_{T}(\pi) \\
\mathrm{ExpF} & =\ln \left(\frac{1}{n_{\pi}} \sum_{\pi \in \Pi} \exp \left(\frac{1}{2} F_{T}(\pi)\right)\right)
\end{aligned}
$$

where $\mathrm{F}=\mathrm{LR}$ or LM, where $F_{T}(\pi)$ denotes the standard LR or LM statistic of $\mathrm{H}_{0}$ : $\lambda=0$ for a given $\pi$, and where $\Pi$ is the set of all possible values of $\pi$ and $n_{\pi}$ is the number of selected elements of $\Pi{ }^{6}$ Andrews and Ploberger (1996) derive the non-standard asymptotic distributions of the supremum, average and exponential statistics and provide finite sample critical values.

In Monte Carlo simulation experiments reported by Andrews and Ploberger (1996), the SupLR and ExpLR tests are found to have very good power properties against various alternatives, followed by the ExpLM statistic. Here we perform an additional simulation experiment, to examine the properties of the test statistics when applied to a time series that is the sum of a stationary and a non-stationary component, as are the real exchange rates in the presence of the Balassa-Samuelson effect. Specifically, the DGP in the simulation experiment is given by (4), (7) and (8) and $\Delta q_{t}$ plays the role of $z_{t}$ in the tests. The autoregressive parameter for the stationary component $x_{t}$ is varied among $\phi \in\{0.8,0.85,0.9,0.95\}$. The standard deviation of the transitory shock $\eta$ takes the values $\sigma_{\eta} \in\{1,2,4,8,16\}$, while the standard deviation of the permanent shock $\varepsilon$ is set equal to 1 throughout. Both $\varepsilon$ and $\eta$ are assumed to be normally distributed. Finally, the correlation between $\varepsilon_{t}$ and $\eta_{t}$ is varied among $\rho \in\{0.0,0.2, \ldots, 0.8\}$. All results are based on 1000 replications for sample size $T=300$, which corresponds with the length of the real exchange rates considered in the empirical application below.

Following the recommendations of Andrews and Ploberger (1996), all tests are implemented using $\Pi=\{0, \pm .01, \pm .02, \ldots, \pm .79, \pm .80\}$ as the set of possible values of $\pi$. Furthermore, all series are demeaned. To obtain appropriate critical values, we simulated the finite sample distributions of the test statistics for this choice of $\Pi$ using 100,000 replications of a driftless random walk. Table 1 shows rejection frequencies of the SupLR test at 10\%, $5 \%$ and $1 \%$ significance levels ${ }^{7}$.

\footnotetext{
${ }^{6}$ Explicit expressions for $L R_{T}(\pi)$ and $L M_{T}(\pi)$, which avoid the necessity of estimating the $\operatorname{ARMA}(1,1)$ model under the alternative, are also given in Andrews and Ploberger (1996).

${ }^{7}$ The corresponding critical values are 4.687, 6.039 and 9.245 , respectively.
} 


\section{- insert Table 1 about here -}

The results in Table 1 suggest that the power of the SupLR test not unexpectedly, decreases with $\phi$ and that it increases with $\rho$ and $\sigma_{\eta}$. Note that the finding of Engel (1999) and Rogers and Jenkins (1995) that changes in relative prices of non-traded goods account for only a small fraction of real exchange rate changes, implies that in practice $\sigma_{\eta}^{2}$ is large relative to $\sigma_{\varepsilon}^{2}$. For example, Engel (2000) reports estimates based on quarterly US/UK data over the period 1970-1995 which imply that $\sigma_{\eta}$ is 100 times larger than $\sigma_{\varepsilon}^{2}$, and under these conditions, our test should have considerable power. Finally, it seems to be recommendable to use a significance level of $10 \%$, to retain at least a reasonable power for values of $\phi$ close to 1 .

Detailed results for the remaining test statistics are not shown here to save space, but these are available upon request. In general, we find that the SupLR test has somewhat better power than the ExpLR test, which in turn performs slightly better than the AveLR test. The same relative performance is observed for the LM tests, and in each case their power is slightly less than the power of the corresponding LR statistics.

To conclude, in this section we have shown that PPP among traded goods can be tested with real exchange rates based upon aggregate price indices, using a simple test which seems to be reliable and useful.

\section{Empirical Results}

In this section we apply the Andrews-Ploberger test described above to relative price levels among a group of 13 industrialized countries ${ }^{8}$. The data are taken from the OECD Main Economic Indicators, and concern the general consumer price index (CPI), and the components of the CPI for (1) food, (2) all goods less food, (3) rent and (4) all services less rent. Note that these four CPI components are collectively exhaustive and mutually exclusive, and represent categories of goods with different degrees of tradability. The sample period covers the complete post-Bretton Woods era until the fixing of the Euro conversion rates, and runs from January 1973 until December $1998 .^{9}$ Monthly nominal exchange rate data are obtained from the IMF

\footnotetext{
${ }^{8}$ These countries and our mnemonics are: Belgium (BEL), Canada (CAN), Denmark (DNK), France (FRA), Germany (GER), Italy (ITA), Japan (JAP), the Netherlands (NLD), Norway (NOR), Spain (SPA), Switzerland (SWI), the United Kingdom (UK), and the United States (US).

${ }^{9}$ Exceptions are the UK all goods less food and all services less rent series, both of which end in July 1988; the Belgium rent series, which starts in June 1976; and the German all services less rent series, which starts in January 1991.
} 


\section{International Financial Statistics.}

As in the simulation experiment, all tests are computed on the demeaned changes in the real exchange rates, using $\Pi=\{0, \pm .01, \pm .02, \ldots, \pm .79, \pm .80\}$ as the set of possible values of $\pi$, while the appropriate finite sample distributions are used to assess the significance of the tests. Below we only report results for the SupLR test. Results for the remaining LR and LM statistics are very similar and are available upon request.

Table 2 contains results for all pairwise real exchange rates based upon the general CPIs. In this and all subsequent tables, the above-diagonal entries are values of the SupLR test statistic while the below-diagonal entries are the corresponding $p$-values based upon the simulated finite sample distribution.

\section{- insert Table 2 about here -}

At 1, 5 and 10\% significance levels, the null hypothesis of no serial correlation can be rejected for 1, 10 and 15 real exchange rates, respectively, out of a total of 78 rates examined. Hence, it seems fair to draw the general conclusion that there is not much evidence in favor of PPP, although there are some exceptions. Notably for the UK, we find evidence (at the 10\% level) of PPP with Belgium, Denmark, France, Germany, Japan and The Netherlands.

Tables 3-6 report results for real exchange rates based upon the CPI components for food, all goods less food, rent, and all services less rent.

\section{- insert Tables 3-6 about here -}

At the $10 \%$ significance level, there is evidence of $\operatorname{ARMA}(1,1)$-type serial correlation in $\Delta q_{t}$, and hence of stationarity of the real exchange rate, in $14,22,19$, and 17 of the 78 cases, respectively. This is well below the tabulated power levels of the test, and hence we can safely conclude that generally there is not much evidence of PPP among traded goods. Note that the number of rejections of the null hypotheses does not appear to be related to the degree of tradability of the goods and services in the different CPI components. For food, which might be regarded to have the smallest non-traded goods component, we actually find less evidence of PPP than for rent and services less rent. Again, there are some specific cases in favor of PPP, and in particular the results for the UK are interesting. Finally, comparing Tables 2 to 6 , we notice that there are many non-overlapping cases with significant test statistics. This suggests that the choice for a price indicator can matter substantially. 


\section{Conclusions}

In this paper we have put forward a simple test for PPP among traded goods, which could also be used for real exchange rates based on a general CPI. The test was shown to be reliable and useful in a simulation experiment with a DGP mimicking the composition of real exchange rates as the sum of a nonstationary and a stationary component. Upon application to bilateral real exchange rates among a group of 13 industrialized countries, we found little evidence in favor of PPP, although there were a few interesting exceptions, in particular for the UK.

As mentioned before, to increase power of tests for PPP, one can either increase the time span of the data or increase the cross-sectional dimension towards a panel of time series. We believe the latter strategy to be fruitful, also for our proposed testing strategy. Hence, a test for white noise against $\operatorname{ARMA}(1,1)$ for a panel of time series might provide even more powerful insights into any empirical evidence of PPP.

\section{References}

Abuaf, N. and P. Jorion, 1990, Purchasing power parity in the long run, Journal of Finance 45, 157-174.

Ardeni, P.G. and D. Lubian, 1991, Is there trend reversion in purchasing power parity?, European Economic Review 35, 1035-1055.

Andrews, D.W.K. and W. Ploberger, 1994, Optimal tests when a nuisance parameter is present only under the alternative, Econometrica 62, 1383-1414.

Andrews, D.W.K. and W. Ploberger, 1996, Testing for serial correlation against an ARMA $(1,1)$ process, Journal of the American Statistical Association 91, 1331-1342.

Baum, C.F., M. Caglayan and J.T. Barkoulas, 2001, Nonlinear adjustment to purchasing power parity in the post-Bretton Woods era, Journal of International Money and Finance 20, 379-399.

Balassa, B., 1964, The purchasing power parity doctrine: a reappraisal, Journal of Political Economy 72, 244-267.

Benninga, S. and A.A. Protopapadakis, 1988, The equilibrium pricing of exchange rates and assets when trade takes time, Journal of International Money and Finance 7, $129-149$.

Canzoneri, M.B., R.E. Cumby, and B. Diba, 1999, Relative labor productivity and the real exchange rate in the long run: evidence for a panel of OECD countries, Journal of International Economics 47, 245-266.

Dumas, B., 1992, Dynamic equilibrium and the real exchange rate in a spatially separated world, Review of Financial Studies 5, 153-180.

De Gregorio, J., A. Giovannini and H.C. Wolf, 1994, International evidence on tradables and nontradables inflation, European Economic Review 38, 1225-1244.

Edison, H.J., 1987, Purchasing power parity in the long run: a test of the dollar/pound exchange rate (1890-1978), Journal of Money, Credit and Banking 19, 376-387. 
Engel, C., 1993, Real exchange rates and relative prices: an empirical investigation, Journal of Monetary Economics 32, 35-50.

Engel, C., 1999, Accounting for US real exchange rate changes, Journal of Political Economy 107, 507-538.

Engel, C., 2000, Long-run PPP may not hold after all, Journal of International Economics 57, 243-273.

Engel, C. and J.H. Rogers, 1996, How wide is the border?, American Economic Review 86, 1112-1125.

Engel, C. and J.H. Rogers, 2001, Deviations from purchasing power parity: causes and welfare costs, Journal of International Economics 55, 29-57.

Feenstra, R.C. and J.D. Kendall, 1997, Pass-through of exchange rates and purchasing power parity, Journal of International Economics 43, 237-261.

Frankel, J.A. and A.K. Rose, 1996, A panel project on purchasing power parity: mean reversion within and between countries, Journal of International Economics 40, 209-224.

Froot, K.A. and K. Rogoff, 1995, Perspectives on PPP and long-run real exchange rates. In G. Grossman and K. Rogoff, editors, Handbook of International Economics, Vol 3, North-Holland, Amsterdam.

Glen, J.D., 1992, Real exchange rates in the short, medium, and long run, Journal of International Economics 33, 147-166.

Grilli, V. and G. Kaminsky, 1991, Nominal exchange rate regimes and the real exchange rate, Journal of Monetary Economics 27, 191-212.

Hansen, B.E., 1996, Inference when a nuisance parameter is not identified under the null hypothesis, Econometrica 64, 413-430.

Haskel, J. and H. Wolf, 2001, The law of one price - A case study, Scandinavian Journal of Economics 103, 545-558.

Heston, A., D.A. Nuxoll and R. Summers, 1994, The differential-productivity hypothesis and purchasing-power parities: some new evidence, Review of International Economics 2, 227-243.

Knetter, M.M., 1993, International comparisons of price-to-market behavior, American Economic Review 83, 473-486.

Lo M.C. and E. Zivot, 2001, Threshold cointegration and nonlinear adjustment to the law of one price, Macroeconomic Dynamics 5, 533-576.

Lothian, J., 1997, Multi-country evidence on the behavior of purchasing power parity under the current float, Journal of International Money and Finance 16, 19-35.

Lothian, J. and M.P. Taylor, 1996, Real exchange rate behavior: the recent float from the perspective of the past two centuries, Journal of Political Economy 104, 488-509.

MacDonald, R., 1996, Panel unit root tests and real exchange rates, Economics Letters 50, 7-11.

Michael, P., A.R. Nobay and D.A. Peel, 1997, Transaction costs and nonlinear adjustment in real exchange rates: an empirical investigation, Journal of Political Economy 105, 862-879.

Ng, S. and P. Perron, 2001, PPP may not hold after all: a further investigation, Annals of Economics and Finance, to appear.

Obstfeld, M. and A.M. Taylor, 1997, Nonlinear aspects of goods-market arbitrage and adjustment: Heckscher's commodity points revisited, Journal of the Japanese and International Economies 11, 441-479.

O'Connell, P.G.J., 1998, The overvaluation of purchasing power parity, Journal of Inter- 
national Economics 44, 1-19.

O'Connell, P.G.J. and S.-J. Wei, 2002, The bigger they are, the harder they fall: Retail price differences across US cities, Journal of International Economics 56, 21-53.

Oh, K.-Y., 1996, Purchasing power parity and unit root tests using panel data, Journal of International Money and Finance 15, 405-418.

Papell, D.H., 1997, Searching for stationarity: purchasing power parity under the current float, Journal of International Economics 43, 313-332.

Papell D.H. and H. Theodoridis, 1998, Increasing evidence of purchasing power parity over the current float, Journal of International Money and Finance 17, 41-50.

Parsley, D.C. and S.-J. Wei, 2001, Explaining the border effect: the role of exchange rate variability, shipping costs, and geography, Journal of International Economics 55, 87-105.

Pedroni, P., 2001, Purchasing power parity tests in cointegrated panels, Review of Economics and Statistics 83, 727-731.

Rogers, J.H. and M. Jenkins, 1995, Haircuts or hysteresis? Sources of movements in real exchange rates, Journal of International Economics 38, 339-360.

Rogoff, K., 1996, The purchasing power parity puzzle, Journal of Economic Literature 34, 647-668.

Samuelson, P.A., 1964, Theoretical notes on trade problems, Review of Economics and Statistics 46, 145-154.

Sarantis, N., 1999, Modeling non-linearities in real effective exchange rates, Journal of International Money and Finance 18, 27-45.

Sarno, L. and M.P. Taylor, 1998, Real exchange rates under the recent float: unequivocal evidence of mean reversion, Economics Letters 60, 131-137.

Sarno, L. and M.P. Taylor, 2001, Purchasing power parity and the real exchange rate, IMF Staff Papers, to appear.

Sercu, P., R. Uppal and C. Van Hulle, 1995, The exchange rate in the presence of transactions costs: implications for tests of purchasing power parity, Journal of Finance 50, 1309-1319.

Taylor, A.M., 2001, Potential pitfalls for the purchasing power parity puzzle? Sampling and specification biases in mean-reversion tests of the law of one price, Econometrica 69, 473-498.

Taylor, M.P. and L. Sarno, 1998, The behavior of real exchange rates during the postBretton Woods period, Journal of International Economics 46, 281-312.

Taylor, M.P., D.A. Peel and L. Sarno, 2001, Nonlinear mean-reversion in real exchange rates: towards a solution to the purchasing power parity puzzles, International Economic Review 42, 1015-1042.

Wu, Y., 1996, Are real exchange rates nonstationary? Evidence from a panel data test, Journal of Money, Credit and Banking 28, 54-63.

Wu, J.L. and S.W. Wu, 2001, Is purchasing power parity overvalued?, Journal of Money, Credit and Banking 33, 804-812. 


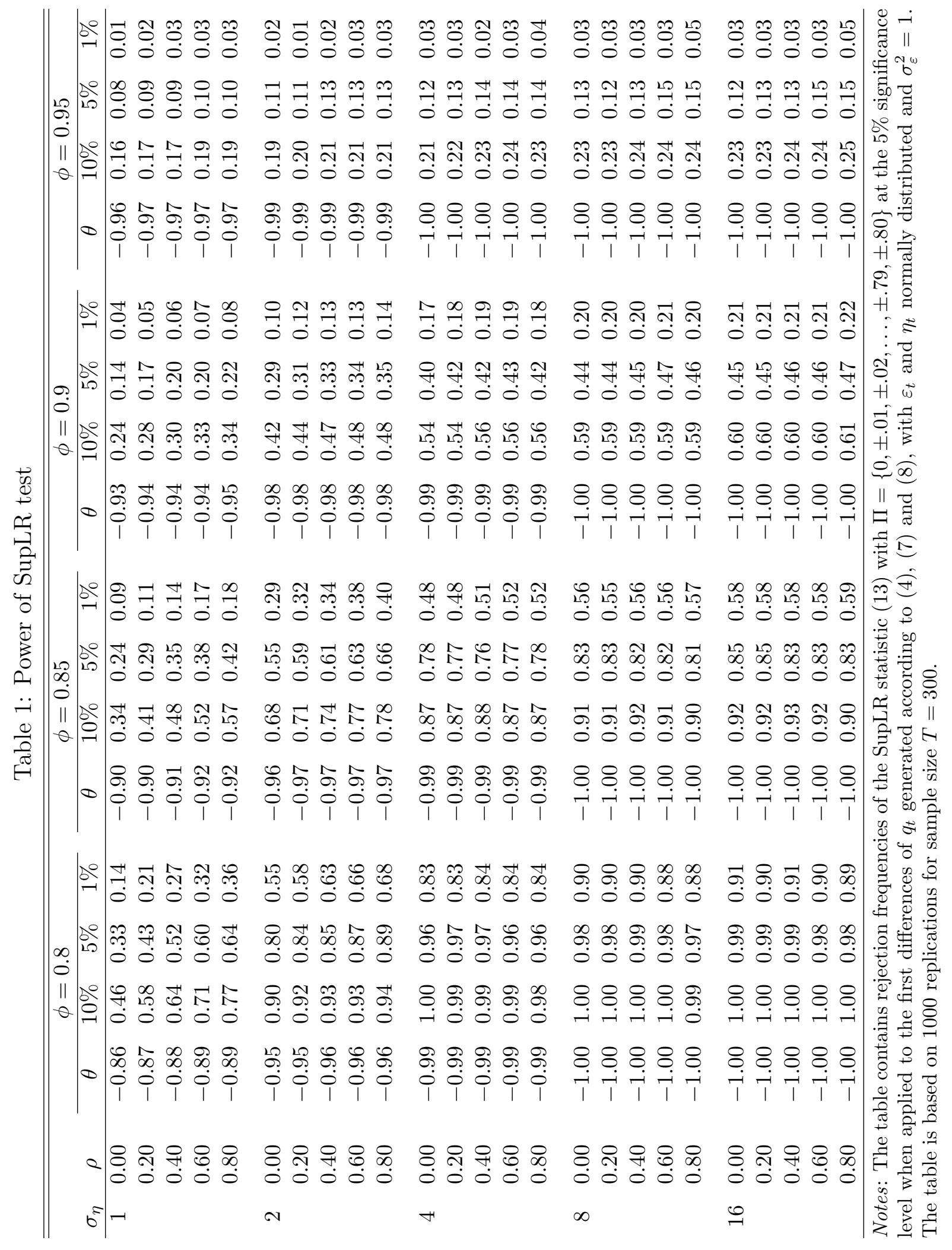


Table 2: Andrews-Ploberger SupLR test for pairwise PPP using real exchange rates based on general CPI

\begin{tabular}{lrrrrrrrrrrrrr}
\hline \hline & BEL & CAN & DNK & FRA & GER & ITA & JPN & NLD & NOR & SPA & SWI & UK & US \\
\hline BEL & & 2.79 & 5.28 & 5.69 & 12.00 & 2.73 & 3.37 & 1.60 & 3.24 & 1.43 & 2.38 & 8.27 & 1.27 \\
CAN & 0.26 & & 2.28 & 2.38 & 1.91 & 3.17 & 3.07 & 1.59 & 0.36 & 2.63 & 0.85 & 2.11 & 0.55 \\
DNK & 0.07 & 0.34 & & 0.98 & 2.29 & 2.40 & 2.91 & 7.61 & 1.44 & 4.00 & 2.05 & 4.93 & 1.04 \\
FRS & 0.06 & 0.33 & 0.68 & & 3.60 & 1.07 & 4.19 & 4.40 & 1.71 & 4.88 & 1.95 & 7.74 & 0.78 \\
GER & 0.00 & 0.42 & 0.34 & 0.17 & & 3.33 & 2.67 & 8.60 & 5.34 & 1.11 & 3.24 & 8.70 & 0.81 \\
ITA & 0.27 & 0.22 & 0.32 & 0.65 & 0.20 & & 6.56 & 1.09 & 0.21 & 3.61 & 1.95 & 3.38 & 2.43 \\
JPN & 0.20 & 0.23 & 0.25 & 0.13 & 0.28 & 0.04 & & 2.10 & 2.66 & 6.34 & 1.49 & 8.60 & 3.67 \\
NLD & 0.49 & 0.49 & 0.02 & 0.12 & 0.01 & 0.64 & 0.38 & & 3.86 & 2.53 & 1.83 & 8.60 & 0.48 \\
NOR & 0.21 & 0.91 & 0.53 & 0.47 & 0.07 & 0.96 & 0.28 & 0.15 & & 3.30 & 1.16 & 0.53 & 0.25 \\
SPA & 0.54 & 0.29 & 0.14 & 0.09 & 0.63 & 0.17 & 0.04 & 0.30 & 0.20 & & 1.48 & 1.42 & 2.59 \\
SWI & 0.33 & 0.72 & 0.39 & 0.41 & 0.21 & 0.41 & 0.52 & 0.44 & 0.62 & 0.52 & & 2.95 & 1.58 \\
UK & 0.02 & 0.38 & 0.09 & 0.02 & 0.01 & 0.19 & 0.01 & 0.01 & 0.84 & 0.54 & 0.24 & & 2.27 \\
US & 0.58 & 0.83 & 0.66 & 0.75 & 0.74 & 0.32 & 0.17 & 0.86 & 0.95 & 0.29 & 0.50 & 0.35 & \\
\hline
\end{tabular}

Notes: The above-diagonal entries are values of the Andrews-Ploberger SupLR test statistic applied to real exchange rates based on general CPI's, using monthly data for the period 1973.1-1998.12. The belowdiagonal entries are the corresponding $p$-values. 
Table 3: Andrews-Ploberger SupLR test on relative prices of food

\begin{tabular}{lrrrrrrrrrrrrr}
\hline \hline & BEL & CAN & DNK & FRA & GER & ITA & JPN & NLD & NOR & SPA & SWI & UK & US \\
\hline BEL & & 1.87 & 4.07 & 10.24 & 9.72 & 2.21 & 3.75 & 0.98 & 0.59 & 1.58 & 2.23 & 6.97 & 0.80 \\
CAN & 0.43 & & 1.45 & 0.52 & 0.94 & 1.98 & 2.62 & 0.57 & 0.82 & 0.58 & 0.45 & 1.48 & 4.27 \\
DNK & 0.14 & 0.53 & & 1.11 & 2.79 & 2.38 & 2.96 & 8.22 & 1.55 & 3.89 & 2.17 & 5.24 & 1.32 \\
FRA & 0.01 & 0.85 & 0.63 & & 3.50 & 0.75 & 2.18 & 2.14 & 3.52 & 7.47 & 4.83 & 4.53 & 0.19 \\
GER & 0.01 & 0.69 & 0.26 & 0.18 & & 3.71 & 3.35 & 3.14 & 6.21 & 1.61 & 8.09 & 4.06 & 0.65 \\
ITA & 0.36 & 0.40 & 0.33 & 0.76 & 0.16 & & 6.84 & 1.00 & 1.45 & 6.81 & 1.38 & 1.85 & 2.41 \\
JPN & 0.16 & 0.29 & 0.24 & 0.36 & 0.20 & 0.03 & & 1.17 & 1.43 & 4.77 & 2.19 & 8.46 & 5.25 \\
NLD & 0.68 & 0.83 & 0.02 & 0.37 & 0.22 & 0.67 & 0.61 & & 1.50 & 5.37 & 3.61 & 3.62 & 0.18 \\
NOR & 0.82 & 0.73 & 0.50 & 0.18 & 0.05 & 0.53 & 0.54 & 0.52 & & 3.24 & 2.30 & 2.27 & 0.83 \\
SPA & 0.50 & 0.82 & 0.15 & 0.02 & 0.49 & 0.03 & 0.10 & 0.07 & 0.21 & & 2.10 & 1.55 & 0.91 \\
SWI & 0.35 & 0.88 & 0.36 & 0.09 & 0.02 & 0.55 & 0.36 & 0.17 & 0.34 & 0.38 & & 1.38 & 0.92 \\
UK & 0.03 & 0.52 & 0.08 & 0.11 & 0.14 & 0.43 & 0.02 & 0.17 & 0.35 & 0.50 & 0.55 & & 3.57 \\
US & 0.74 & 0.12 & 0.57 & 0.97 & 0.80 & 0.32 & 0.08 & 0.97 & 0.73 & 0.70 & 0.70 & 0.18 & \\
\hline
\end{tabular}

Notes: The above-diagonal entries are values of the Andrews-Ploberger SupLR test statistic applied to the relative prices of food expressed in a common currency, using monthly data for the period 1973.1-1998.12. The below-diagonal entries are the corresponding $p$-values.

Table 4: Andrews-Ploberger SupLR test on relative prices of all goods less food

\begin{tabular}{lrrrrrrrrrrrrr}
\hline \hline & BEL & CAN & DNK & FRA & GER & ITA & JPN & NLD & NOR & SPA & SWI & UK & US \\
\hline BEL & & 2.21 & 24.97 & 1.97 & 11.64 & 1.92 & 2.58 & 9.41 & 12.93 & 1.10 & 1.08 & 6.59 & 0.65 \\
CAN & 0.36 & & 1.53 & 2.54 & 2.45 & 4.26 & 2.67 & 1.04 & 0.30 & 3.73 & 0.96 & 1.48 & 1.75 \\
DNK & 0.00 & 0.51 & & 2.79 & 10.35 & 1.40 & 1.69 & 21.35 & 8.20 & 4.44 & 6.79 & 2.76 & 0.72 \\
FRA & 0.41 & 0.30 & 0.26 & & 3.83 & 1.43 & 4.06 & 4.41 & 8.17 & 2.10 & 1.83 & 7.74 & 0.86 \\
GER & 0.00 & 0.31 & 0.01 & 0.15 & & 3.87 & 2.56 & 13.70 & 11.30 & 0.17 & 3.71 & 9.32 & 1.27 \\
ITA & 0.42 & 0.12 & 0.55 & 0.54 & 0.15 & & 6.43 & 3.06 & 1.72 & 1.43 & 2.08 & 5.32 & 3.13 \\
JPN & 0.29 & 0.28 & 0.47 & 0.14 & 0.30 & 0.04 & & 1.35 & 1.89 & 5.90 & 1.05 & 7.34 & 3.76 \\
NLD & 0.01 & 0.66 & 0.00 & 0.11 & 0.00 & 0.23 & 0.56 & & 18.85 & 1.82 & 5.42 & 8.66 & 0.34 \\
NOR & 0.00 & 0.93 & 0.02 & 0.02 & 0.00 & 0.46 & 0.42 & 0.00 & & 7.15 & 1.00 & 1.07 & 0.99 \\
SPA & 0.64 & 0.16 & 0.11 & 0.38 & 0.97 & 0.54 & 0.05 & 0.44 & 0.03 & & 0.94 & 1.61 & 2.74 \\
SWI & 0.64 & 0.68 & 0.03 & 0.44 & 0.16 & 0.38 & 0.66 & 0.07 & 0.67 & 0.69 & & 1.95 & 1.75 \\
UK & 0.04 & 0.52 & 0.27 & 0.02 & 0.01 & 0.07 & 0.03 & 0.01 & 0.65 & 0.49 & 0.41 & & 1.57 \\
US & 0.80 & 0.46 & 0.77 & 0.72 & 0.58 & 0.22 & 0.16 & 0.91 & 0.67 & 0.27 & 0.45 & 0.50 & \\
\hline
\end{tabular}

Notes: The above-diagonal entries are values of the Andrews-Ploberger SupLR test statistic applied to the relative prices of all goods less food expressed in a common currency, using monthly data for the period 1973.1-1998.12. The below-diagonal entries are the corresponding $p$-values. 
Table 5: Andrews-Ploberger SupLR test on relative prices of rent

\begin{tabular}{lrrrrrrrrrrrrr}
\hline \hline & BEL & CAN & DNK & FRA & GER & ITA & JPN & NLD & NOR & SPA & SWI & UK & US \\
\hline BEL & & 3.57 & 12.2 & 0.42 & 1.10 & 0.63 & 1.60 & 2.08 & 1.13 & 0.82 & 2.86 & 22.88 & 1.76 \\
CAN & 0.18 & & 0.97 & 2.28 & 2.31 & 4.93 & 3.97 & 0.54 & 0.24 & 3.84 & 0.60 & 4.76 & 1.16 \\
DNK & 0.00 & 0.68 & & 10.43 & 15.03 & 2.66 & 1.24 & 28.53 & 9.58 & 3.99 & 0.99 & 2.49 & 1.20 \\
FRA & 0.88 & 0.35 & 0.01 & & 1.29 & 2.01 & 2.85 & 5.12 & 1.03 & 0.52 & 1.78 & 14.10 & 0.91 \\
GER & 0.64 & 0.34 & 0.00 & 0.58 & & 1.93 & 1.95 & 19.29 & 1.70 & 0.56 & 0.72 & 17.68 & 0.89 \\
ITA & 0.81 & 0.09 & 0.28 & 0.40 & 0.41 & & 5.90 & 0.07 & 0.75 & 0.96 & 1.09 & 8.13 & 4.30 \\
JPN & 0.49 & 0.14 & 0.59 & 0.26 & 0.41 & 0.05 & & 0.32 & 2.70 & 9.92 & 0.33 & 13.73 & 3.10 \\
NLD & 0.38 & 0.84 & 0.00 & 0.08 & 0.00 & 0.99 & 0.92 & & 3.23 & 1.30 & 7.74 & 13.69 & 0.44 \\
NOR & 0.63 & 0.95 & 0.01 & 0.66 & 0.47 & 0.76 & 0.28 & 0.21 & & 1.85 & 8.38 & 0.83 & 1.53 \\
SPA & 0.73 & 0.15 & 0.14 & 0.85 & 0.83 & 0.68 & 0.01 & 0.58 & 0.43 & & 0.32 & 2.47 & 3.41 \\
SWI & 0.25 & 0.82 & 0.68 & 0.45 & 0.77 & 0.64 & 0.92 & 0.02 & 0.02 & 0.92 & & 4.32 & 1.67 \\
UK & 0.00 & 0.10 & 0.31 & 0.00 & 0.00 & 0.02 & 0.00 & 0.00 & 0.73 & 0.31 & 0.12 & & 4.34 \\
US & 0.45 & 0.62 & 0.61 & 0.70 & 0.71 & 0.12 & 0.23 & 0.88 & 0.51 & 0.19 & 0.47 & 0.12 & \\
\hline
\end{tabular}

Notes: The above-diagonal entries are values of the Andrews-Ploberger SupLR test statistic applied to the relative prices of rent expressed in a common currency, using monthly data for the period 1973.1-1998.12. The below-diagonal entries are the corresponding $p$-values.

Table 6: Andrews-Ploberger SupLR test on relative prices of all services less rent

\begin{tabular}{lcrrrrrrrrrrrr}
\hline \hline & BEL & CAN & DNK & FRA & GER & ITA & JPN & NLD & NOR & SPA & SWI & UK & US \\
\hline BEL & & 6.12 & 1.49 & 5.62 & 0.86 & 4.60 & 1.86 & 0.42 & 5.65 & 0.30 & 0.95 & 6.98 & 3.77 \\
CAN & 0.05 & & 3.11 & 4.87 & 1.84 & 3.48 & 4.03 & 2.88 & 1.42 & 3.21 & 1.84 & 5.19 & 1.14 \\
DNK & 0.52 & 0.22 & & 0.67 & 3.30 & 5.28 & 1.23 & 2.88 & 0.56 & 2.86 & 4.54 & 5.06 & 2.05 \\
FRA & 0.06 & 0.09 & 0.79 & & 2.23 & 2.67 & 2.88 & 2.66 & 5.04 & 1.39 & 1.32 & 5.27 & 2.17 \\
GER & 0.72 & 0.43 & 0.20 & 0.35 & & 1.96 & 0.23 & 14.42 & 0.37 & 5.08 & 2.34 & & 5.37 \\
ITA & 0.10 & 0.18 & 0.07 & 0.28 & 0.41 & & 4.29 & 2.08 & 1.45 & 3.02 & 2.29 & 1.68 & 3.35 \\
JPN & 0.43 & 0.14 & 0.60 & 0.25 & 0.96 & 0.12 & & 1.40 & 1.53 & 6.61 & 1.94 & 4.98 & 3.02 \\
NLD & 0.89 & 0.25 & 0.25 & 0.28 & 0.00 & 0.38 & 0.55 & & 2.51 & 1.31 & 1.38 & 5.09 & 1.53 \\
NOR & 0.06 & 0.54 & 0.83 & 0.08 & 0.90 & 0.53 & 0.51 & 0.31 & & 2.50 & 0.43 & 2.27 & 1.58 \\
SPA & 0.93 & 0.21 & 0.25 & 0.55 & 0.08 & 0.23 & 0.04 & 0.57 & 0.31 & & 0.90 & 2.82 & 3.29 \\
SWI & 0.69 & 0.43 & 0.11 & 0.57 & 0.33 & 0.34 & 0.41 & 0.55 & 0.88 & 0.71 & & 2.81 & 1.92 \\
UK & 0.03 & 0.08 & 0.08 & 0.07 & & 0.47 & 0.09 & 0.08 & 0.35 & 0.26 & 0.26 & & 1.17 \\
US & 0.16 & 0.62 & 0.39 & 0.36 & 0.07 & 0.20 & 0.23 & 0.51 & 0.50 & 0.20 & 0.42 & 0.62 & \\
\hline
\end{tabular}

Notes: The above-diagonal entries are values of the Andrews-Ploberger SupLR test statistic applied to the relative prices of all services less rent expressed in a common currency, using monthly data for the period 1973.1-1998.12. The below-diagonal entries are the corresponding $p$-values. 